\title{
Order, Disorder, and Re-Order State of Lysozyme: Aggregation Mechanism by Raman Spectroscopy
}

\begin{abstract}
Sandip Dolui ${ }^{\mathrm{a}}$, Animesh Mondal ${ }^{\mathrm{a}}$, Anupam Roy ${ }^{\mathrm{a}}, \mathrm{Uttam} \mathrm{Pal}^{\mathrm{a}}$, Supriya Das ${ }^{\mathrm{a}}$, Achintya Saha ${ }^{\mathrm{b}}$, Nakul C Maitia*
\end{abstract}

a Structural Biology and Bioinformatics Division, Indian Institute of Chemical Biology, Council of Scientific and Industrial Research, 4, Raja S.C. Mullick Road, Kolkata 700032, India

b Department of Chemical Technology, University of Calcutta, 92 Acharya Prafulla Chandra Road, Calcutta 700009, India

* Address correspondence to Nakul C. Maiti, Division of Structural Biology and Bioinformatics, CSIR-Indian Institute of Chemical Biology, 4, Raja S.C. Mullick Road, Kolkata 700032

E-mail:ncmaiti@iicb.res.in

Phone: +91-33-2499-5940 


\section{Circular Dichroism measurements:}

Circular dichroism spectra were recorded by using a JASCO J-815 spectropolarimeter (Jasco, Easton, MD). Far-UV CD spectra were recorded from 195 to $250 \mathrm{~nm}$ at room temperature using a $1 \mathrm{~mm}$ path quartz cuvette, resolution of $0.2 \mathrm{~nm}$, a scan rate of $50 \mathrm{~nm} / \mathrm{min}$. lysozyme concentration was $10 \mu \mathrm{M}$ at different incubation time points. Each spectrum was the average of the three consecutive scans. 

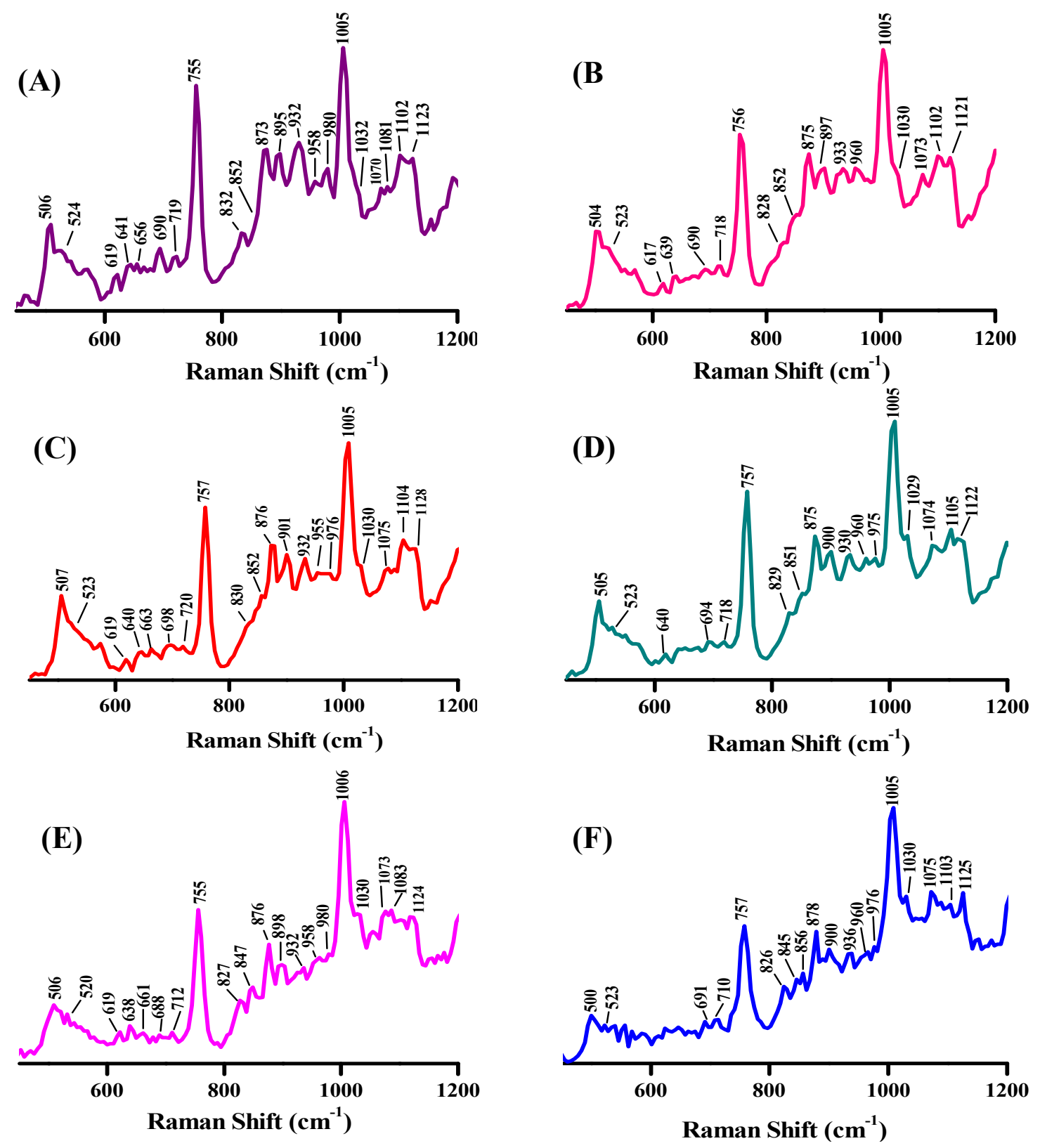

Figure S1: $532 \mathrm{~nm}$ excited Raman spectra (500-1200 $\mathrm{cm}^{-1}$ ) of HEWL. (A) In hanging drop single crystal acetate buffer, $(0.1 \mathrm{M}) \mathrm{pH}$ 4.8. (B) Lysozyme powder. (C) Monomer at $0 \mathrm{~h}$ : incubation condition ( $\mathrm{HEWL}=20 \mathrm{mg} / \mathrm{ml}, \mathrm{pH}=1.6, \mathrm{~T}=60^{\circ} \mathrm{C}$ ). (D) Oligomer; incubated time $9 \mathrm{~h}$. (E) ) Protofibril; incubated time 39 h. (F) Fibril, incubation time $60 \mathrm{~h}$. 

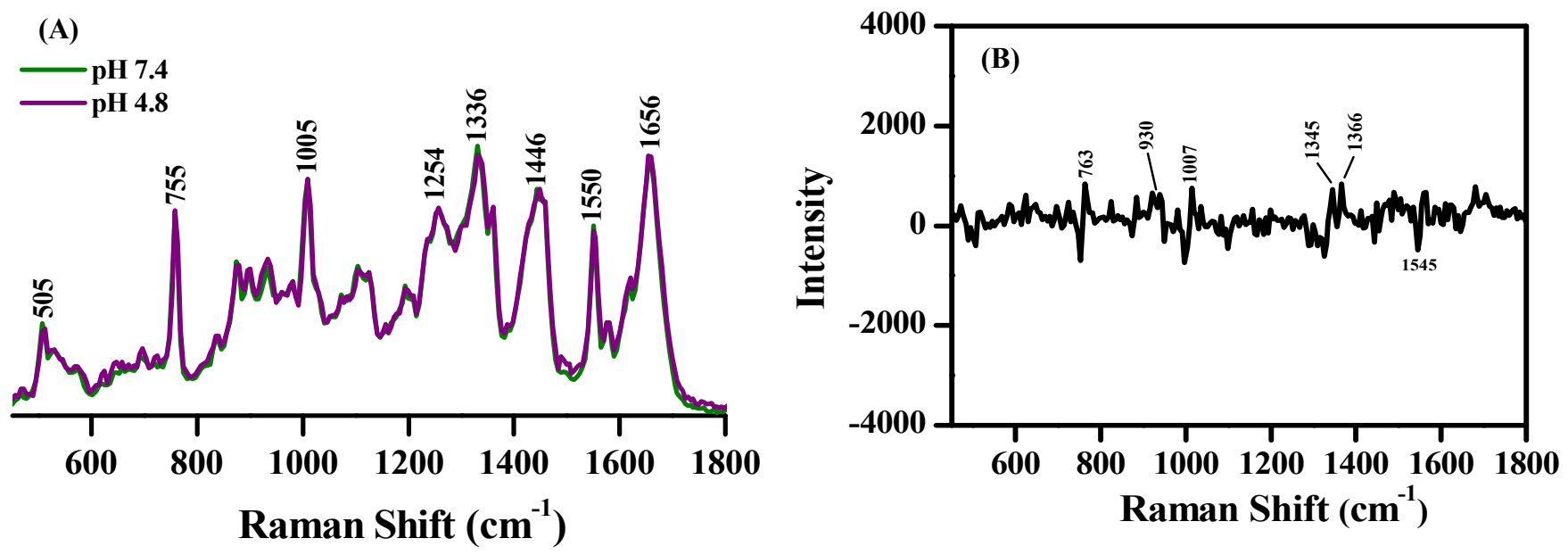

Figure S2: Superimposition and Raman spectra taken at HEWL crystals. (A) Overlap of $\mathrm{pH} 7.4$ (green) and $\mathrm{pH} 4.8$ (violet). (B) Difference spectrum of the crystals. 


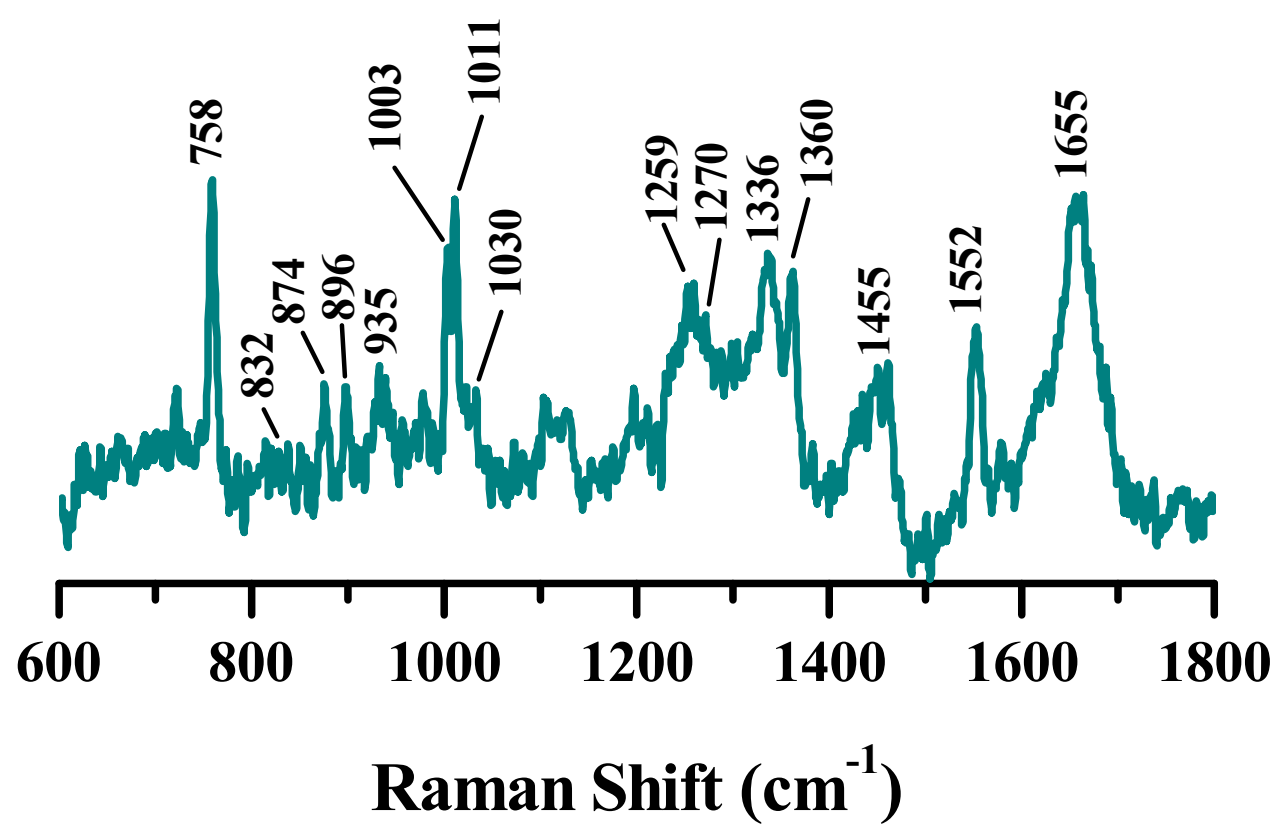

Figure S3. Solution state Raman spectrum of HEWL excited at $532 \mathrm{~nm}$. Laser power source 35 $\mathrm{mW}$. Sample: $20 \mathrm{mg} / \mathrm{ml}, \mathrm{pH} 1.6(25 \mathrm{mM} \mathrm{HCl}, 100 \mathrm{mM} \mathrm{NaCl})$. 


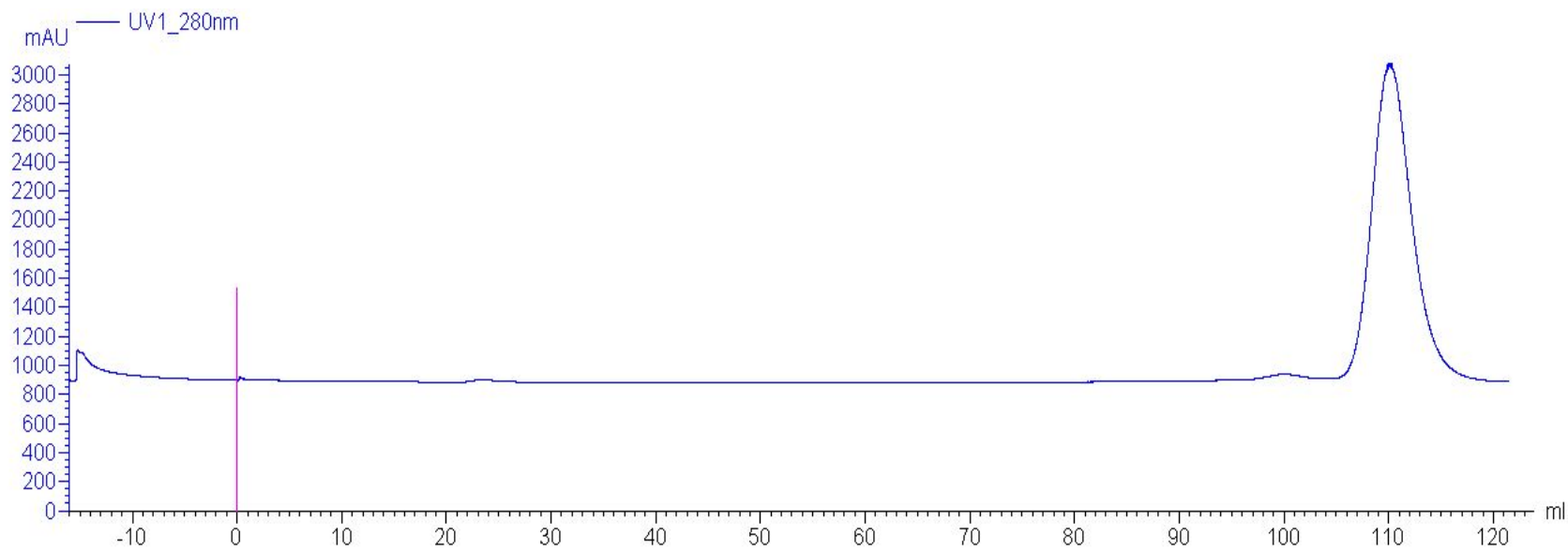

Figure S4. Size-exclusion chromatography of HEWL solution. $500 \mu \mathrm{M}$ lysozyme solution was prepared in tris $\mathrm{HCl}$ buffer and run through Superdex16/600 column to check its conformation. A single peak indicates the protein is in monomeric conformation. 


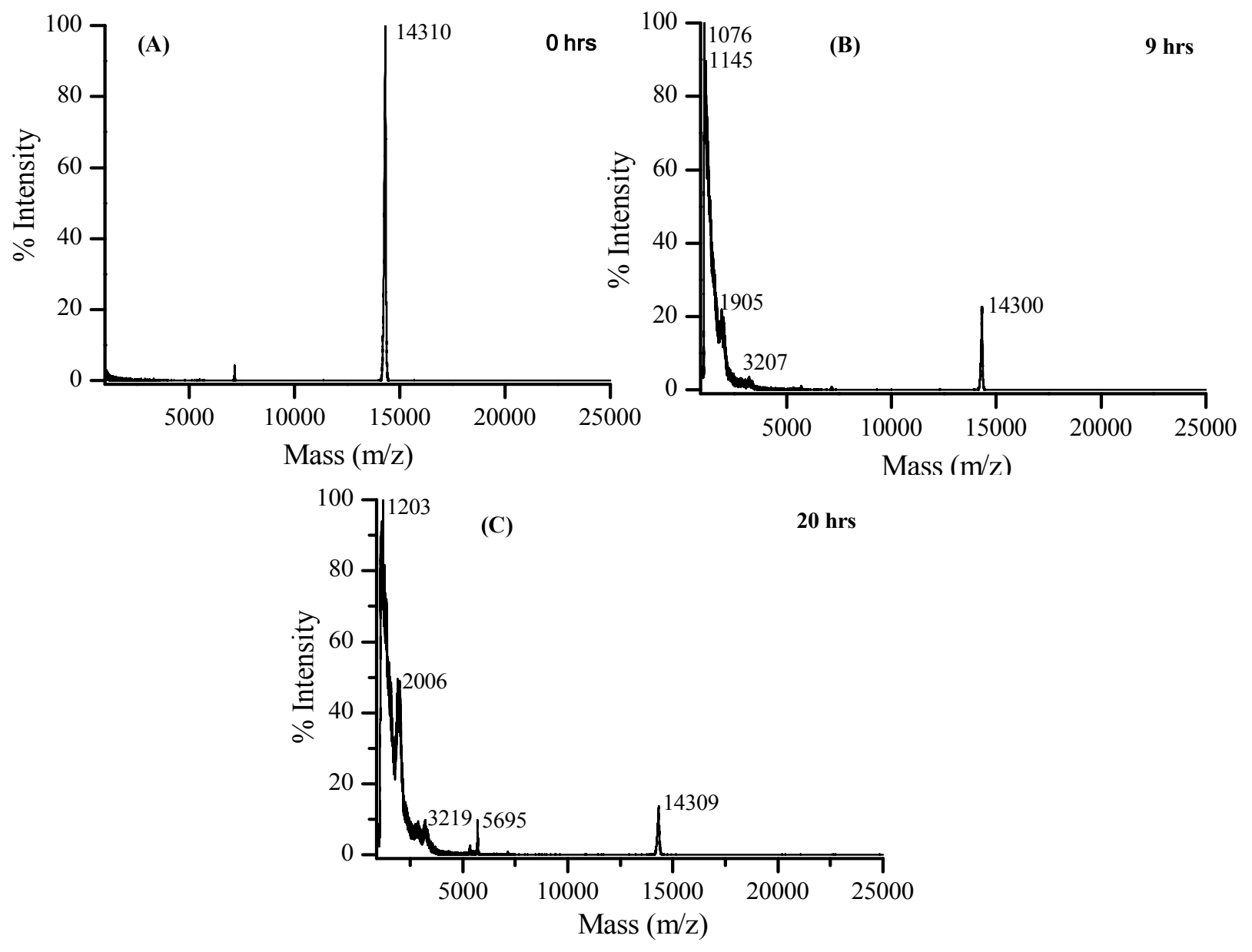

Figure S5: Mass spectrometry (MALDI-TOF) analysis obtained from a solution of lysozyme. (A) Lysozyme at $0 \mathrm{~h}$ of incubation (B) Lysozyme after incubation of $9 \mathrm{~h}$ at $60^{\circ} \mathrm{C}$. (C) Lysozyme after incubation of $20 \mathrm{~h}$ at $60^{\circ} \mathrm{C}$. 


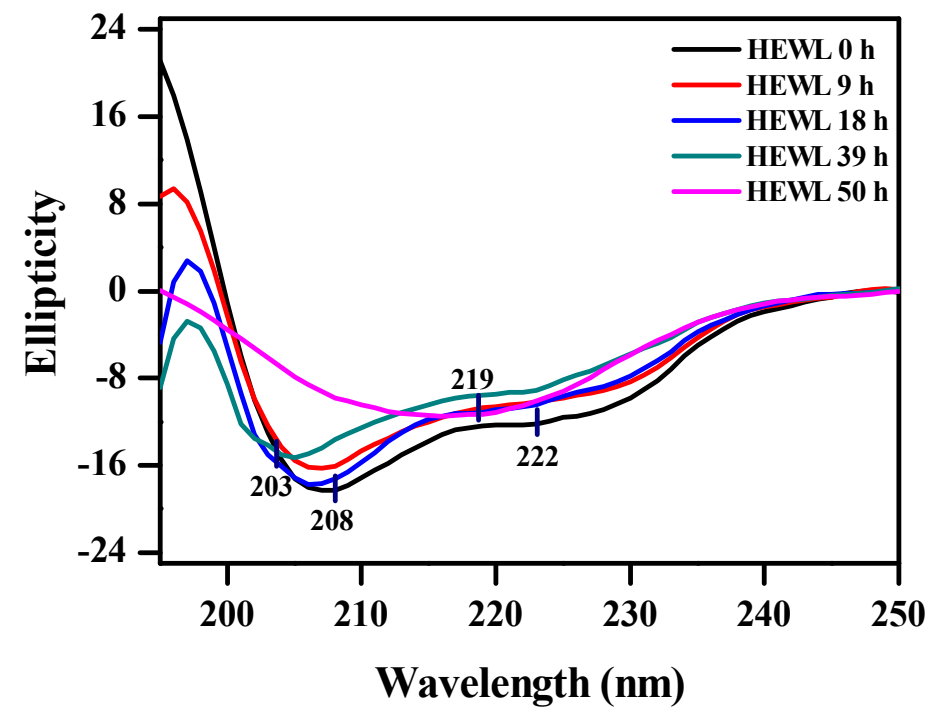

Figure S6 . Far UV-CD spectra of HEWL at different time point of incubation: $0 \mathrm{~h}$ (black), $6 \mathrm{~h}$ (red), $18 \mathrm{~h}$ (blue), $39 \mathrm{~h}$ (green), $50 \mathrm{~h}$ (pink). Protein concentration and other solution condition were similar to Figure 2. All CD spectra were measured on a JASCO J-815 spectropolarimeter at room temperature $\left(24^{\circ} \mathrm{C}\right)$.

The $0 \mathrm{~h}$ samples show typical negative band at 208 and $222 \mathrm{~nm}$ and indicated predominant $\alpha$ helical conformation. This band pattern was persistent for quite a long time, including the time frame when protein attained oliogmeric assembly structure. However, a typical structural transformation from helical to $\beta$-sheet structure occurred with a signatory negative band at $\sim 219$ $\mathrm{nm}$. These observations were very consistent with our results obtained from Raman spectroscopic measurements and analysis. 


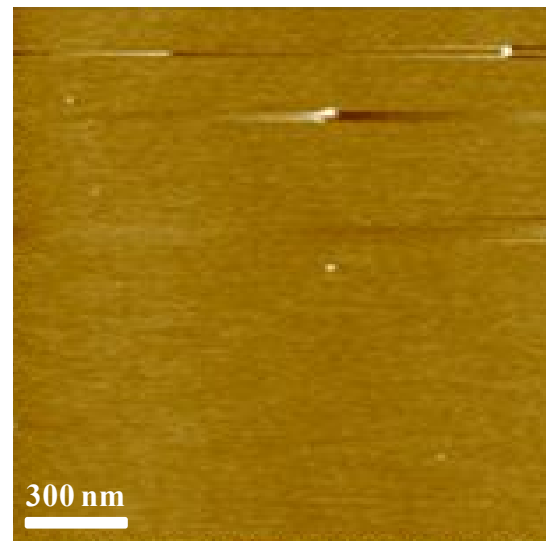

Figure S7: Atomic force microscopy images of lysozyme after $0 \mathrm{~h}$ of incubation, (incubation condition, [lysozyme] $=20 \mathrm{mg} / \mathrm{ml}, \mathrm{T}=60^{\circ} \mathrm{C}, \mathrm{pH}=1.6,100 \mathrm{mM} \mathrm{NaCl}$ ). 